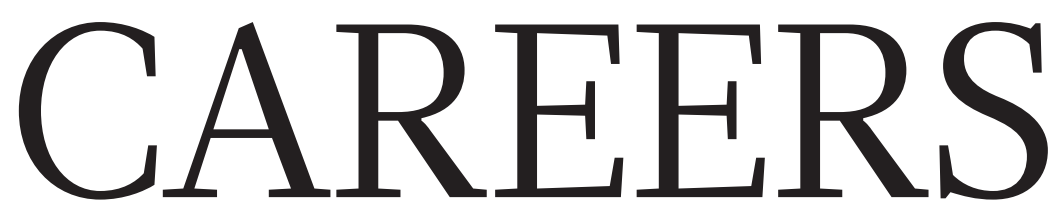

COURAgE Speak up now to resolve misunderstandings p.135
ONLINE Career resources from our scientific community at nature.com/careers
Social Follow us on Twitter at twitter.com/NatureCareers

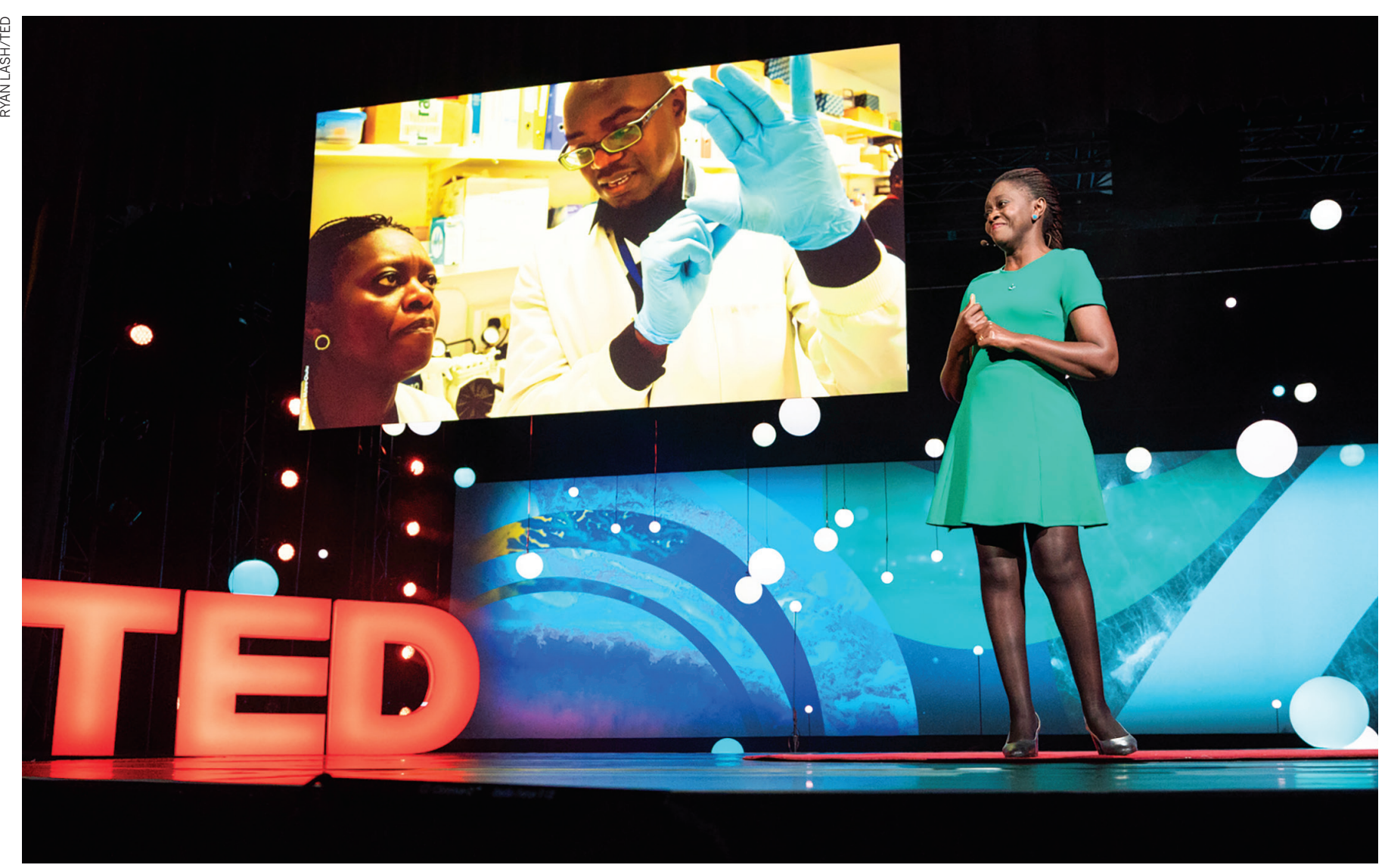

Malaria immunologist Faith Osier says that speaking on the TED platform has increased her visibility, as well as given her a sense of validation.

\title{
ENGAGEMENT
}

\section{Under the TED spotlight}

Three researchers share what they learnt from presenting their science at a TED conference.

$\mathrm{T}$

1ED talks offer researchers a chance to reach much larger audiences than those

they might encounter at a routine lab meeting or symposium presentation, thanks to their availability online at www.ted.com.

The flagship TED conference is held each year in Vancouver, Canada, and affiliated events such as TEDWomen or TEDGlobal - as well as independent satellite events, known as TEDx - offer further opportunities for scientists worldwide to step onto the stage. Popular talks are often viewed millions of times - a level of exposure that can bring notoriety, both good and bad. Nature spoke to several scientists-turned-TED presenters for insights into how their talks have influenced their presentation style, and how researchers can maximize the value of such exposure.

\section{FAITH OSIER \\ Step out of your comfort zone}

Malaria immunologist at the Kenya Medical Research Institute-Wellcome Trust Research Programme in Kilifi.

I attended my first TED event - the TEDGlobal conference in Arusha, Tanzania - in August
2017. While I was there, I saw an announcement about how to apply to become a TED fellow, so I did and I was later selected. (Those who give TED talks are either nominated or do so after becoming a TED fellow.)

TED fellows receive access to a mentor for one year, or roughly 12 mentoring sessions. Beyond that, they become part of a community of fellows from many disciplines, who share information ranging from how to negotiate speaking fees to how investors and entrepreneurs work.

I'm a scientist who is used to bone-dry meetings. The scale of the 2018 TED conference in Vancouver blew my mind - there were musicians, artists, historians, engineers and $>$ 
- even a technologist flying drones. Putting together my TED talk made me realize that I'm a researcher who is working on new vaccines to prevent malaria - a disease that is killing people - and that it's a big idea that I'm passionate about. It's good to get out of your own mole-hole and allow your mind to think big.

One of the biggest challenges I had to face was that TED talks are very 'American'. The format comes across to me as showing off. It was outside my comfort zone to blow my own horn, or to showcase how great I am. I did want to be on the platform, but I had to overcome a lot of internal discomfort to do so.

During the preparation, the TED team helped me to remove the jargon from my talk and to break down the content of each slide so that a broad audience could understand it. For example, in my original slide deck, I used a picture of an older African man to convey that 50 years ago, researchers took malaria antibodies from older people who had survived malaria and then injected them into younger people.

But it proved too distracting to focus on why these older vaccines don't work well enough. It got in the way of the main point of my fiveminute talk: how we are using new technologies to identify the proteins involved in a successful immune response to malaria to make a better vaccine. You have to offer enough detail without getting too much into the nitty-gritty.

My TED talk gave me a sense of validation, not to mention more visibility than I could otherwise have had. I've found that showing my talk is a powerful way of introducing myself at speaking events. I also get invited to speak at more events than I used to. This year, for example, I've been invited to speak at the Bill \& Melinda Gates Foundation Grand Challenges annual meeting in Addis Ababa; the Annual International Biomedical Students meeting, which is the largest conference for medical students in Europe; and the Godrej Leadership Forum in Mumbai, India.
I went into my TED talk hoping that I would encounter a funder who could pump a lot of cash into my research. That hasn't happened yet, but there is a slow-burn effect. It's been exciting to watch the number of views rise to 1.3 million.

\section{SHOHINI GHOSE Embrace storytelling}

\section{Quantum physicist at Wilfrid Laurier University in Waterloo, Canada.}

So far, I have given six TED talks. My first was at TEDxWaterlooWomen in Canada, in 2012. During that experience, I learned about the TED Fellows Program. The application process was refreshingly non-academic: they weren't interested in your CV, only in how you wanted to make an impact on the world. That appealed to me.

In 2014, I became a TED fellow and gave my first talk at the main TED conference in Vancouver, discussing the connections between quantum theory and chaos theory - and highlighting an article I had published in Nature (S. Chaudhury et al. Nature 461, 768-771; 2009) that had garnered a lot of press attention.

I work hard to find the balance in my talks, so that I have enough detail to match accuracy with clarity. Scientists tend to put in all the details, but it's more about the storytelling.

Before I became a TED fellow, I had founded the Centre for Women in Science at Wilfrid Laurier University in Waterloo. I was exploring not just my own research in physics, but also how scientists can build the best, most inclusive physics community. Because I was already following a slightly atypical path in academia, the TED Fellows Program was a good fit. Last year,

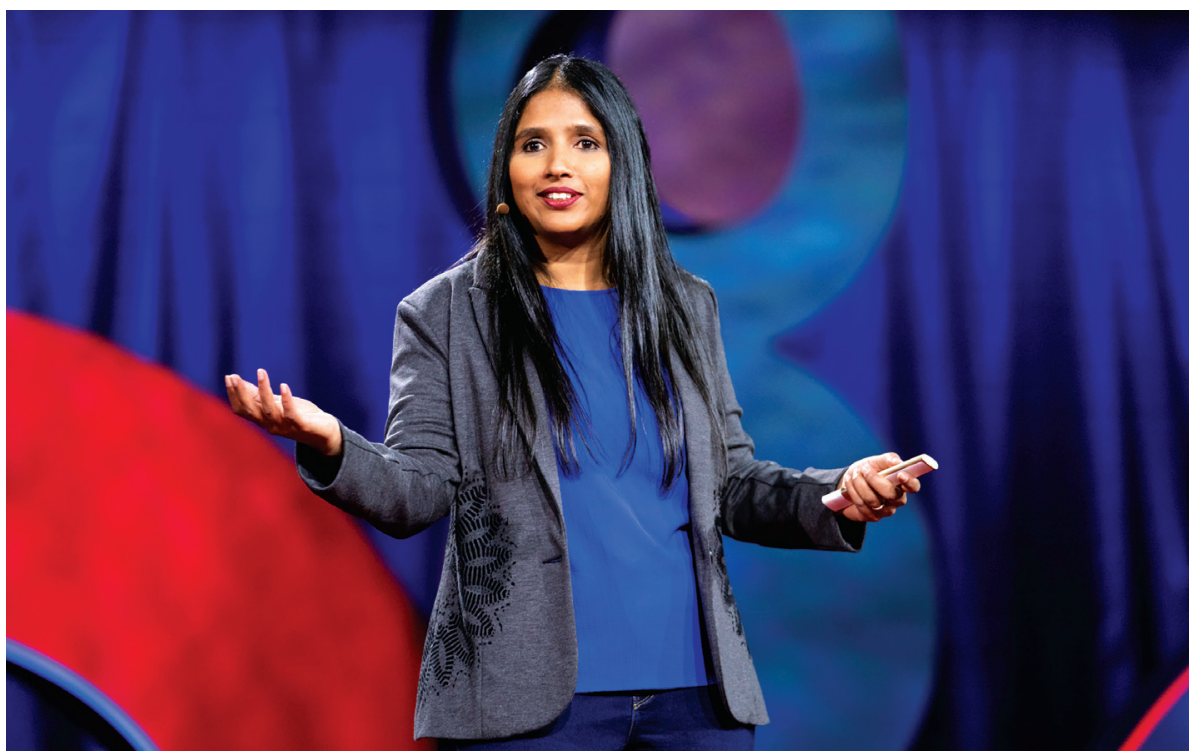

The TED Fellows Program has helped physicist Shohini Ghose to amplify her voice.

A talk with impact
"Recognize the big idea that you are
working on and present it with energy
and enthusiasm." Faith Osier, KEMRI-
Wellcome Trust Research Programme, Kilifi.
"Craft a story that balances clarity and
accuracy." Shohini Ghose, Wilfrid Laurier
University, Waterloo, Canada.
"Say one thing - your big point -
cleanly. Articulate that main point while
putting it into a context that will make it
interesting to anyone." Gavin Schmidt,
NASA Goddard Institute for Space Studies,
New York City.

I gave a ten-minute talk at the TEDWomen conference in Palm Springs, California, that explained quantum computing.

The TED experience has broadened my career track. It's incredibly energizing and inspiring that people in the fellows' network are always there to support each other. Since joining the programme, I've worked with artists and musicians. With Tharanga Goonetilleke, a TED fellow and opera singer from Sri Lanka, I developed an art-science-music project featuring women scientists from around the world.

I've become more courageous - and amplified my voice - by being part of the TED Fellows Program. As my media profile expands, I get more invitations to speak, and not all of them are limited to the academic world. I've done episodes of the popular science programmes BBC Horizon and PBS Nova; both have huge viewerships. I'm also publishing a book about some of my work.

However, the TED spotlight also comes with consequences. The majority of my colleagues have been very supportive. But there is a more conservative group in academia who feel that TED might dilute - some call it 'dumbing down' - the science, and that this watered-down version is harmful to science. Then, there are the trolls, who are eager to criticize women who communicate science. As a woman, if I talk confidently, I come across as being arrogant. Throughout my career, I've had some frightening experiences, even threats of physical harm, that in some cases required police escorts.

Because of those experiences, I craft my talks to avoid being too controversial. For example, I'll joke that I have the power of invisibility, as a humorous way of expressing how women often aren't seen.

Although giving TED talks has been a huge net positive, that is only because I chose to prioritize it in my life and career. Being engaged with the public doesn't come for free in terms of time. One fewer TED talk would 
allow me to publish extra research or to go to other conferences. I don't think that it's for everybody. It has to match your career goals.

\section{GAVIN SCHMIIDT Invest the time}

\section{Climate scientist at the NASA} Goddard Institute for Space Studies in New York City.

It pays to invest in putting together a highquality presentation. I spent three months collating my talk on the emergent patterns of climate change for the main TED conference in 2014. At the beginning of the process, I was casting about for an appropriate metaphor, and the jigsaw puzzle presented itself as a visual way of representing the million lines of code that piece together all the variables that must be modelled to achieve a realistic, dynamic picture of the global climate.

Everything in a TED talk has to be created from scratch, so I had to make my own jigsaw pieces. Once I had that metaphor, I had the advantage of being able to tap into some great NASA images. For the past five years, I've benefited enormously from that three-month investment in my graphics.

The TED team encouraged me to go more deeply into things that I would normally have thought too complex for a general audience. Basically, you can make one point in your talk, and you can go deep into the details, as long as you take the audience with you and build up to your main point. Each slide should push that point further rather than go off on an ancillary detail.

It goes back to some basic communication skills: know your audience and know what you want to say. Overall, my presentations are now much less cluttered, and they have more impact than they used to (see 'A talk with impact'). My talks are graphics-heavy and I use the imagery to convey a narrative. Being able to point people who have contacted me with questions to the TED talk also saves me an enormous amount of time.

Communicating high-profile, controversial science is a bit of a gamble. If you have something genuine to share, it can push you and your science forwards. But if the science is subsequently not held up, it can pull you down - and that might hold you back or serve as a millstone around your neck for years. It's a bit of a two-edged sword. It's gone badly for only a handful of scientists, but it's good to remember that TED talks are a high-impact opportunity. It pays to be careful, because your talk can come to define you.

COLUMN

Speak up now

\section{Resolve minor misunderstandings before they snowball, says Jamie Sugrue.}

$\mathrm{T}$ rinity College Dublin, where I'm a $\mathrm{PhD}$ student in comparative immunology, offers a class called 'Planning and Preparing for your PhD'. It aims to equip doctoral students like me with the skills and advice necessary to deal with both unforeseen and predictable situations that might arise during their studies.

I think it's an exercise in futility. No amount of planning will teach you as much during your $\mathrm{PhD}$ programme as will your own experience. Still, those who have found themselves in bizarre or peculiar situations might be able to pass on useful advice. I am one such person.

During 2018 - the first year of my $\mathrm{PhD}$ studies - my supervisor and I flew to Cambridge, UK, to visit a collaborator. As the three of us sat down to lunch, my supervisor asked me if I did much cooking. I replied that I did, and said that I tended to cook even when I went home to southern Ireland, because my mother usually prepared mostly 'meatand-two-veg' dishes. My supervisor looked confused, turned to our collaborator and said, “That's so surprising, because Jamie's mother makes the most fantastic chocolate! His family owns the most wonderful chocolate factory!"

We should pause here for a moment to take in the fact that I don't own a chocolate factory. Nor does my mother or my family.

This faulty assumption on my supervisor's part did not arise completely from thin air. To provide some context, I am from County Kerry in southwest Ireland, which hosts Skelligs Chocolate, a well-known artisanal chocolate manufacturer. My family home's geographic proximity to the company and my having gifted the lab with chocolate from there in the past had led to a classic 'wires-crossed' situation.

Hoping to avoid embarrassing my supervisor or myself, I did not correct her assertion. Instead, I simply changed the subject, thinking that the topic would never arise again.

\section{YOU WANT ME TO...WHAT?}

But several months later, it did. My supervisor was a co-organizer of the 25th International Hepatitis $\mathrm{C}$ conference in October 2018, here in Dublin, and was holding a meeting in her office. She appeared in the lab in a rush to ask if I could briefly join the meeting. When I entered her office, she introduced me to two of her co-organizers, and then asked if my family would be willing

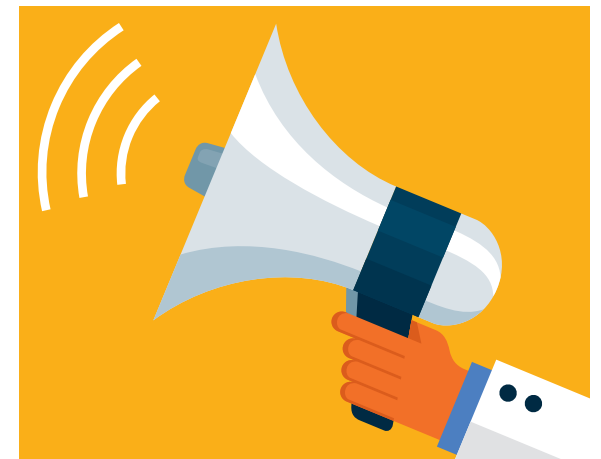

to make bespoke chocolate for the invited speakers at the conference.

I stood there, stunned by my own silliness for not having foreseen a situation like this. Conversation about the chocolate continued while I tried to work out how I was going to get myself out of this unfathomable situation.

On reflection, I realized that the only way out was to bite the bullet and explain the whole situation to my supervisor. So the next day, I broke the news that my family did not, in fact, own the chocolate business, or have any ties to it beyond its location close to my family home. I was exceptionally fortunate in that she thought the whole scenario quite funny.

It is eminently possible that my disinclination towards speaking up came about because Irish people, and perhaps also English people, are often more deferential than our US counterparts to those in positions of authority, such as principal investigators. Were a US PhD student in my shoes at the time, she or he might simply have interjected with, "Hey, that's crazy!" rather than letting the wound fester, as I did.

My aversion to a potentially uncomfortable correction in the short term led me down a path that could have had greater consequences if the stakes had been higher.

Although I expect that I would have spoken up about something more serious, my misstep, in any event, is a perfect illustration of how even the most trivial of mix-ups can lead to an awkward and uncomfortable situation. So, no matter how unpleasant it might seem at the time, you must speak up and correct the error. Otherwise, you could find yourself frantically Googling how difficult it is to make bespoke chocolate at short notice.

Jamie Sugrue is a PhD student in comparative immunology at Trinity College Dublin. 